\title{
O PAPEL DA EDUCAÇÃO TÉCNICA PARA UMA PRODUÇÃO MAIS SUSTENTÁVEL
}

\author{
Plínio Gabriel João ${ }^{1}$ \\ Diego Henrique Rosa Penha² \\ Fagner de Melo Silva ${ }^{3}$
}

\section{Embasamento teórico}

\subsection{Sustentabilidade}

O tema sustentabilidade está sendo amplamente discutido nos últimos anos para tratar da existência da sociedade humana, pois o termo está condicionado aos melhoramentos das condições ambientais. O termo sustentabilidade começou a ser amplamente divulgado a partir de 1987, após ser apresentado no relatório das Nações Unidas, preparado pela primeira-ministra norueguesa Gro Harlem Brundtland, que definiu desenvolvimento sustentável como "satisfazer as necessidades do presente sem comprometer a capacidade das gerações futuras de satisfazer as próprias necessidades (Secretaria Especial de Comunicação Social, 2012). Segundo Bellen (2005, p. 16) "as crescentes dúvidas em relação ao futuro do meio ambiente são uma das consequências das várias transformações que marcaram a segunda metade do breve século XX”. Anteriormente, Herfindall e Herrera, publicaram, no século XIX, artigos baseados em projeções estatísticas que relacionavam o crescimento e o consumo da população ao nível de recursos naturais existentes, apresentando como resultados cenários que hoje nos refletem (RATTNER, 1977).

Para o Global Footprint Network (2017), uma maneira simples de avaliar o desenvolvimento sustentável é usando o Índice de Pegada Ecológica e Desenvolvimento Humano (IDH). Uma Pegada Ecológica menor que 1,7 hectares globais por pessoa torna essas demandas de recursos globalmente replicáveis. As Nações Unidas consideram um IDH superior a 0,8 sendo um "desenvolvimento humano muito elevado".

\footnotetext{
${ }^{1}$ Centro Paula Souza. E-mail: plinio.joao@etec.sp.gov.br.

${ }^{2}$ Centro Paula Souza. E-mail: diego.penha@etec.sp.gov.br.

${ }^{3}$ Centro Paula Souza.E-mail: fagner.silva@etec.sp.gov.br.
} 


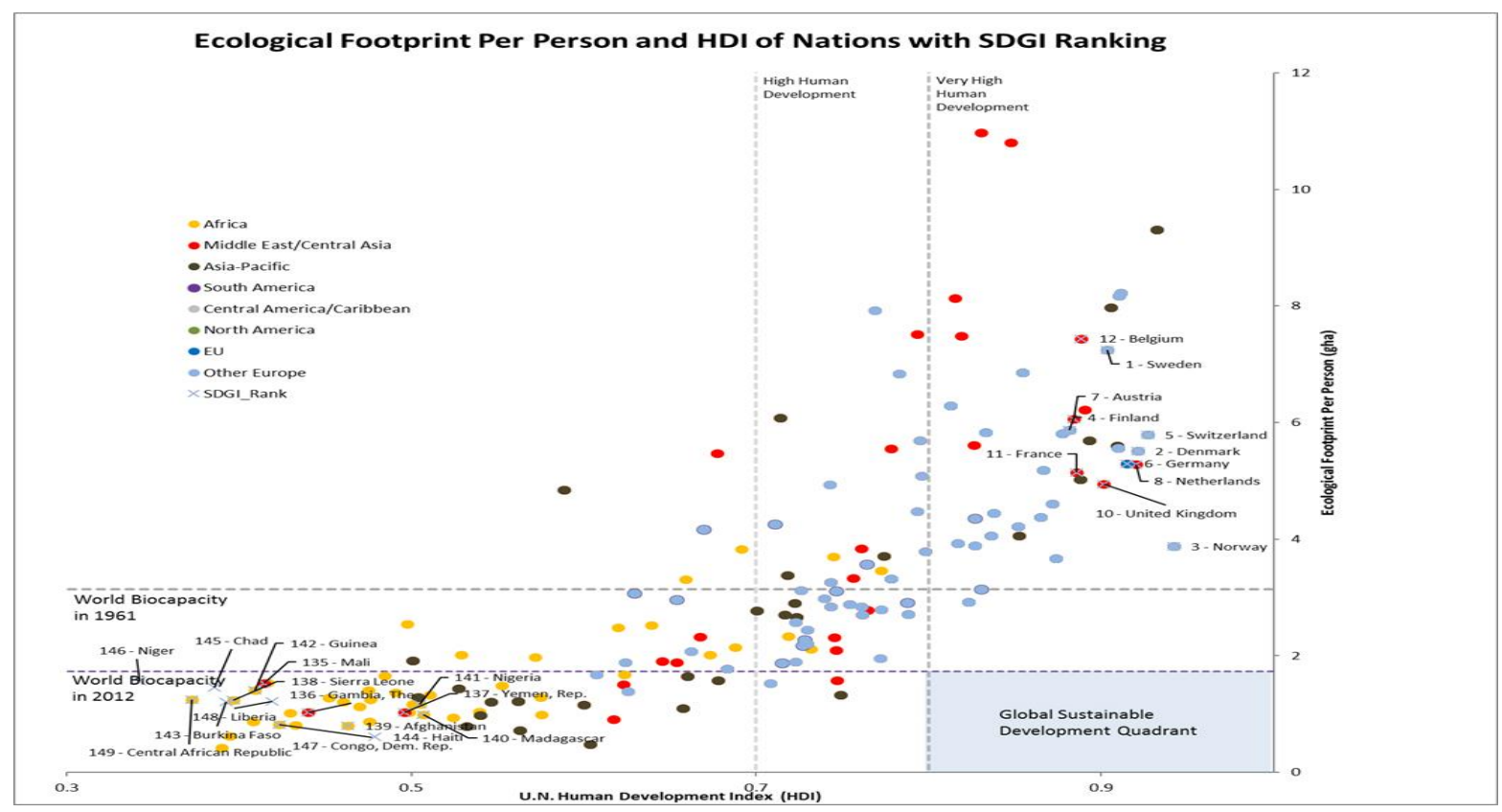

Gráfico 1: Pegada Ecológica por pessoa e países do IDH com ranking SDGI - Fonte: (GLOBAL FOOTPRINT NETWORK, 2017). Disponível em: 〈https://goo.gl/2nUvzo〉. Acesso em: 06 mar. 2017

Observe o gráfico 1 (GLOBAL FOOTPRINT NETWORK, 2017), considerando-se as duas variáveis em questão. Medir essas duas variáveis revela que poucos países estão próximos de alcançar o desenvolvimento sustentável, apesar da crescente adoção dos Objetivos de Desenvolvimento Sustentável e de outras políticas que buscam aumentar o bem-estar sem sacrificar o meio ambiente (GLOBAL FOOTPRINT NETWORK, 2017).

Para Richard Walker, especialista em desenvolvimento sustentável da Universidade de Indiana, nos Estados Unidos, as catástrofes ambientais, como o efeito estufa, buraco da camada de ozônio, entre outros, são consequências da má utilização e exploração dos recursos materiais, devido ao crescimento desorganizado das economias e à grande aglomeração de pessoas nos centros urbanos (LIMA \& VIEIRA, 2008). Segundo Walker, existem caminhos a serem percorridos para regularização e controle dos impactos ambientais; porém, o grande desafio é equilibrar o crescimento econômico dos países com a preservação ambiental.

Esse novo cenário deverá ser construído em três vias: população, organizações e governo. Nele, a população deve consumir com consciência, as organizações devem adaptar seus processos, repensando o consumo dos recursos naturais, e o governo deve criar leis regulamentadoras e fiscalizá-las.

Para Kotler (2011), as empresas devem entender corretamente quais são as necessidades, os desejos e a demanda de determinados mercados (bairros, cidades, países...) para que possam inovar na criação de novos produtos, serviços e processos. Tendo como base esse pensamento, é possível colocar a pergunta: será que podemos afirmar que a população tem o poder sobre as formas de como produzir e de consumo dos recursos naturais? Mediante o pensamento de Kotler, podemos considerar que sim, mas, para que isso aconteça, as necessidades e desejos da sociedade deveriam estar debruçados sobre produtos totalmente sustentáveis. E a educação: seria possível formarmos cidadãos e profissionais com consciência sustentável? Paulo Freire, em sua Terceira carta pedagógica afirma: "Se a educação sozinha, não transforma a sociedade, sem ela tampouco a sociedade muda. " (FREIRE, 2000, p. 67), porém, Marx (1973, pg. 24) relata que "O modo de produção da vida material condiciona o desenvolvimento da vida social, política e intelectual em geral. Não é a consciência dos homens que determina o seu ser; é o seu 
ser social que, inversamente, determina a sua consciência.” Seria, então, a colocação de Karl Marx o grande obstáculo que a educação devia enfrentar?

\subsection{Produção mais limpa}

É notório que o aquecimento das manufaturas se dá pelo modelo capitalista, que tem como premissa a lucratividade baseada no consumo. Marx (1973) aponta alguns problemas no modelo capitalista, como o "fetichismo da mercadoria", quando o cenário domina os industriais, destacando o valor dos produtos acabados e os próprios produtos tornam-se necessidades e desejos da sociedade. Mediante o contexto, existe uma grande preocupação com a escassez dos recursos naturais necessários para atender aos níveis de consumo da sociedade mundial já apontados pelo Global Footprint Network (2017). Alguns estudiosos apostavam que apenas o crescimento econômico em si proporcionaria melhores condições de vida à sociedade e que o próprio sistema equilibraria o consumo dos recursos naturais.

Tais pensamentos não se confirmaram, e essas atitudes causaram grandes danos ao meio ambiente. Percebeu-se que não se tratava apenas de haver um crescimento econômico para manter o equilíbrio, mas da existência de um conjunto de fatores, entre eles, a interação entre a sociedade e o meio ambiente. Para Afonso (2016), a sustentabilidade requer meios estratégicos de planejamento, o que vai de encontro ao capitalismo predominante, pois o sistema busca obter maior lucratividade em curtos espaços de tempo.

Entretanto, ao longo da história, foram criadas algumas estratégias visando a equilibrar os reflexos gerados pelas manufaturas. Na década de 80, inicia-se um novo pensamento de produção, "Produção Enxuta", com uma sistemática de produção mais eficiente, flexível, ágil e inovadora; diferente do modelo de produção em massa fordista. A produção enxuta, ou lean manufacturing, trata-se de técnicas que eliminam desperdícios, passando a produzir de acordo com a demanda do mercado e não mais em "Massa/Escala".

A aplicação do lean manufacturing faz com que as organizações repensem seus processos, evitando desperdícios como:

- $\quad$ superprodução;

- estoque;

- espera;

- transporte;

- defeitos;

- movimentação nas operações;

- processamento.

Outras iniciativas como PmaisL (Produção Mais Limpa) estão sendo implementadas pelas manufaturas com foco, não apenas no maior volume de vendas e no aumento de receitas, mas também na utilização dos recursos que serão utilizados para a confecção dos produtos, como energia, água, e nos reflexos que estes poderiam causar ao meio ambiente.

Várias organizações investiram na implementação desse modelo e, como resultado, conseguiram atrair um maior número de adeptos aos seus produtos, além de estar minimizando o consumo de recursos naturais. Um bom exemplo dessa implementação é o caso da Panasonic: a organização sempre está atenta à utilização dos recursos naturais em seus processos, procurando continuamente reduzir o consumo de energia, de $\mathrm{CO} 2$, poupando e reutilizando a água como subproduto em seu ciclo de suprimentos. A empresa aplicou o modelo "Green Procurement", visando a transformar a indústria em uma "fábrica verde" (CÂMARA DO JAPÃO, 2017) 
Quando estamos tratando de PmaisL, a visão da empresa não deve estar preocupada apenas com o sistema de produção, mas com todo o ciclo de vida do produto - desde sua produção, consumo e o destino final. Se observarmos, já existe uma mudança na postura de algumas organizações, mas, para que possamos reverter todos os danos causados ao meio ambiente, não basta apenas a iniciativa das organizações. É necessário que também a sociedade se conscientize da necessidade de um relacionamento sustentável entre cliente e fornecedor que sempre vise à preservação do meio ambiente, além de que ela esteja motivada, mobilizada para assumir responsabilidades e propor ações.

Uma proposta interessante de ser implementada dentro das organizações, sejam de grande ou pequeno porte, por toda sociedade seria a integração da logística reversa com aplicação dos " $5 \mathrm{R}$ 's" (reciclar, recusar, repensar, reduzir e reutilizar), com vistas à diminuição do consumo, de forma mais consciente, que dê folego ao meio ambiente e desenvolva uma sociedade com atitudes sustentáveis.

\subsection{A educação técnica com saberes sustentáveis}

Com a Revolução Industrial, no século XVIII e XIX, na Inglaterra, acumulou-se grande capital devido ao fortalecimento das manufaturas e dos produtos consumidos no continente Europeu. Nessa fase do processo de industrialização, desenvolveram-se novos conceitos e técnicas de produção que propiciaram o avanço do capitalismo do século XX. Essas técnicas buscavam a maximização da produção (produção em massa), pois a demanda por produtos desenvolvidos por essas manufaturas era de grande escala. Diante dessa forte demanda, portanto, as indústrias da época adotaram um sistema de produção padronizado que tinha como um dos seus princípios produzir mais com o menor intervalo de tempo possível. Assim, surgia, nessa época, o modelo da administração científica que teve como referências iniciais Taylor e Fayol.

Com o passar dos anos, houve a necessidade da criação de cursos técnicos para atender aos novos postos de trabalhos gerados pelas manufaturas. Havia, portanto, a necessidade de mão de obra mais qualificada para atuar nas grandes linhas de produção. Tal qualificação buscava atender às especificidades técnicas e produtivas da manufatura, como torneiros mecânicos, fresadores entre outros. (ORNELLAS \& MONTEIRO, 2006)

Já atualmente, com a forte presença da globalização e do fácil acesso à informação e seu processamento também facilitado, os conceitos e teorias clássicos foram se adaptando às novas teorias e cedendo espaço para elas, pois as necessidades do mercado diversificaram-se. Dessa forma, houve a imprescindibilidade de reestruturar as manufaturas, a mão de obra e as habilidades e competências dos funcionários para atuar nesse novo cenário. (MAILLAT, 2002)

Assim, a educação técnica vem, juntamente, transformando-se no decorrer dessas mudanças e, para Pacheco (2012), a formação profissional deve estudar e aplicar o uso consciente dos recursos naturais dentro e fora das organizações com responsabilidade socioambiental. Para Berna (2015, pg. 10), entretanto, "a educação ambiental, à medida que se assume como educação mais política do que técnica, assume também o processo de formadora da identidade política e cultural de um povo". Segundo Porcher, Ferrant \& Blot (1975, p. 4),

[...] a pedagogia do meio ambiente é, incontestavelmente, uma pedagogia da ação, isto é, dos alunos tomarem a seu próprio cargo problemas, precisamente porque estes problemas dizem respeito a todos em sua vida cotidiana, e não poderiam ser regulados pela simples recitação de informações. 
Quando pensamos em educação para o meio ambiente, o principal aspecto que surge em nossas mentes é a contribuição para formação de cidadãos conscientes, aptos a decidir e atuar na realidade socioambiental de uma forma responsável. Para que esses aspectos aconteçam, é necessário haver mais do que informações e conceitos: as escolas técnicas devem trabalhar com atitudes, com formação de valores, com o ensino e aprendizagem de procedimentos não somente documental, devem mensurar as atitudes e valores no dia a dia da sala de aula.

\section{Conclusão}

Diante dos fatos apresentados, podemos concluir que a educação técnica tem um papel essencial não só para uma produção mais limpa, como também na criação de cidadãos (consumidores) mais sustentáveis, pois, os conceitos desenvolvidos poderão ser replicados nas manufaturas, grupos sociais como também em seus próprios lares. Isso porque a educação técnica tem papel de agente transformador, que podemos caracterizar como pilar principal para uma sociedade mais sustentável, mas para sustentação desse pilar, necessitamos de políticas públicas com um olhar mais acentuado nessas necessidades, pois, é a política que administrará parte do equilíbrio econômico, incentivos fiscais para uma produção mais sustentável, fiscalização, investimentos e centros de pesquisa para um desenvolvimento produtivo mais sustentável e incentivos para criação e manutenção de cooperativas de reciclagem.

\section{Referências}

AFONSO, C. M.. Sustentabilidade - Caminho ou Utopia. São Paulo: Annablume, 2006.

ALCANTRA, V. Inserção Curricular da Educação Ambiental. Curitiba/PR: IESDE Brasil, 2012.

BELLEN, H. M. Indicadores de Sustentabilidade: uma análise comparativa. Rio de Janeiro: FGV, 2005.

BERNA, V. S. A mudança começa em nós. Revista do Meio Ambiente, p. 10-11, 2005.

CÂMARA DO JAPÃO. Atividade de Sustentabilidade da Panasonic do Brasil. Disponível em: $<$ http://jp.camaradojapao.org.br/upload/files/Press\%20release\%20sustentabilidade\%20Panaso nic\%20do\%20Brasil.pdf $>$. Acesso em: 13 de março de 2017.

FREIRE, P. Pedagogia da indignação: cartas pedagógicas e outros escritos. São Paulo: Unesp, 2000.

GLOBAL FOOTPRINT NETWORK. (s.d.). Sustainable development: two indices, two different views. Disponível em: <http://www.footprintnetwork.org/2016/07/20/measuresustainable-development-two-new-indeces-two-different-views/>. Acesso em: 06 abr. 2017.

KOTLER, P. Administração de Marketing. São Paulo: Atlas, 2011.

LIMA, R. D.; VIEIRA, V. A Terra não aguenta. Veja, p. 10-12, 2008

MAILLAT, D. Globalização, meio inovador e sistemas territoriais de produção. Interações Revista Internacional de Desenvolvimento Local, p. 9-16, 2002. 
MARX, K. Contribuição para a crítica da economia política. Lisboa: Estampa, 1973.

ORNELLAS, T. C.; MONTEIRO, M. I. Aspectos históricos, culturais e sociais do trabalho. REBEn - Revista Brasileira de Enfermagem, p. 552-555, 2006.

PACHECO, J. F. Avaliação da Aprendizagem na Escola da Ponte. Rio de Janeiro: WAK, 2012.

PORCHER, L.; FERRANT, P.; BLOT, B. Pedagogia do Meio Ambiente. Lisboa: Socicultur, 1975.

RATTNER, H. O esgotamento dos recursos naturais: catástrofe interdependência? Revista de Administração de Empresas, n. 4, p. 5-46, 1977.

Secretaria Especial de Comunicação Social. Em Busca De Um Mundo Sustentável. Em Discussão, n. 11(3), p. 58, jun. 2012. 